\title{
SMS Fiber Structure for Temperature Measurement Using an OTDR
}

\author{
A. M. HATTA ${ }^{1,2^{*}}$, K. INDRIAWATI ${ }^{1}$, T. BESTARIYAN $^{1}$, \\ T. HUMADA ${ }^{1}$, and SEKARTEDJO ${ }^{1}$ \\ ${ }^{1}$ Engineering Physics Department, Faculty of Industrial Technology, Institut Teknologi Sepuluh Nopember, Surabaya, \\ 60111, Indonesia \\ ${ }^{2}$ Physics Department, Faculty of Science, Jazan University, Gizan, 22822, Kingdom of Saudi Arabia \\ *Corresponding author: A. M. HATTA_E-mail: amhatta@ep.its.ac.id
}

\begin{abstract}
A singlemode-multimode-singlemode (SMS) fiber structure for temperature measurement using an optical time domain reflectometer (OTDR)-based interrogation system is proposed. A temperature measurement range of $40^{\circ} \mathrm{C}-195^{\circ} \mathrm{C}$ with a resolution of $0.12^{\circ} \mathrm{C}$ and a linearity of 0.992 could be achieved for the multimode fiber (MMF) graded index with a length of $60 \mathrm{~mm}$. It was also demonstrated that two-point temperature measurement with two SMS fiber structures as temperature sensors could be made. The proposed temperature measurement system offered a high resolution and also benefited from a simple configuration with a capability of multi-point temperature measurement.
\end{abstract}

Keywords: Temperature sensor, SMS fiber structure, OTDR

Citation: A. M. HATTA, K. INDRIAWATI, T. BESTARIYAN, T. HUMADA, and SEKARTEDJO, "SMS Fiber Structure for Temperature Measurement Using an OTDR,” Photonic Sensors, DOI: 10.1007/s13320-013-0104-9.

\section{Introduction}

Multimode interference effects occurring in singlemode-multimode-singlemode (SMS) fiber structures have been investigated and utilized for both sensing and signal processing applications [1-8]. These optical devices offer an all-fiber solution with the advantages of easiness of fabrication, packaging, and interconnection over other optical fibers. The SMS fiber structure is fabricated using a commercial fusion splicer by splicing a multimode fiber (MMF) section between two singlemode fibers (SMF). In the SMS fiber structure, the interference between modes in the MMF section occurs along the MMF length. The SMS fiber structure can generate the minimum or maximum interference at specific MMF lengths. By precisely optimizing the MMF length, different device functions can be developed.

SMS fiber structures demonstrate temperature dependence $[9,10]$. The temperature changes will affect the refractive index and dimensions of the fiber core and cladding, in turn the interference between modes in the MMF section will change, and thus the output response changes. It was demonstrated that the effect of temperature on the wavelength response of the SMS fiber structurebased device could be compensated by using a suitable packaging material [11]. This temperature dependence can also be exploited to develop a temperature sensor. Some techniques can be utilized to extract the temperature information from the SMS

Received: 7 November 2012 / Revised version: 30 May 2013

(C) The Author(s) 2013. This article is published with open access at Springerlink.com 
fiber structure sensor, for example by measuring the temperature-induced shift in the peak wavelength of its spectrum [12], an intensity-based interrogation system [13], or a ratiometric power interrogation system [14].

Techniques in [12-14] could only be used for single-point measurement. In some industrial processes or a structural health monitoring system, a multi-point or quasi-distributed temperature measurement system is needed $[15,16]$. One possible technique for the multi-point temperature measurement is utilizing an optical time domain reflectometer (OTDR). Normally, the OTDR measures the reflected light or the return loss and detects events such as connection, splice, cracks, within the optical fiber network. The SMS fiber structure's connection and the temperature change in the SMS fiber structure can be detected as an event in the OTDR. Thus, some SMS fiber structures in implementation of the multi-point temperature sensors can be detected as the OTDR's events. In this paper, an experimental investigation into a temperature measurement using the SMS fiber structure as the temperature sensor and the OTDR as the interrogator is presented.

\section{Experimental procedure}

A schematic structure of the SMS fiber structure as shown in Fig. 1(a) was formed by splicing the MMF with a length of $L_{\mathrm{MMF}}$ between two SMFs. A standard SMF28 (ITU-T recommendation G.655) was used as the SMF. The MMF graded index (ITU-T recommendation G.651) with a core radius of $25 \mu \mathrm{m}$ was used. The SMS fiber structure described above was fabricated using a precision Fitel Nc S324 fiber cleaver and a compact fusion splicer of Sumitomo Electric type-25e. Some SMS fiber structures were fabricated with the $L_{\mathrm{MMF}}$ of $50 \mathrm{~mm}, 60 \mathrm{~mm}, 70 \mathrm{~mm}$, and $80 \mathrm{~mm}$. These lengths, $L_{\mathrm{MMF}}$, were chosen because of the easiness of their cutting process. The two SMF lengths of about $250 \mathrm{~m}$ were used to construct the SMS fiber structure.

The experimental setup was built, as shown in Fig. 1(b). The SMS fiber structure was attached to a hot plate in which its temperature could be controlled by a precision temperature controller, while a digital thermometer 6001 HDT sensor probe was also attached to accurately measure the temperature. The OTDR of JDSU MTS 8000 series with an operational wavelength of $1550 \mathrm{~nm}$ was used to detect the event induced by the temperature changes in the SMS fiber structure. The OTDR measured the attenuation of reflected light or return loss and its location within the optical fiber network. It had a maximum distance of $5 \mathrm{~km}$ and the attenuation resolution of $0.001 \mathrm{~dB}$. In this experiment, the temperature measurement was carried out in the temperature range of $40{ }^{\circ} \mathrm{C}-200^{\circ} \mathrm{C}$ with an increment of $5^{\circ} \mathrm{C}$.

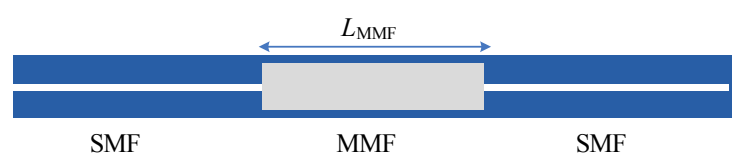

(a)

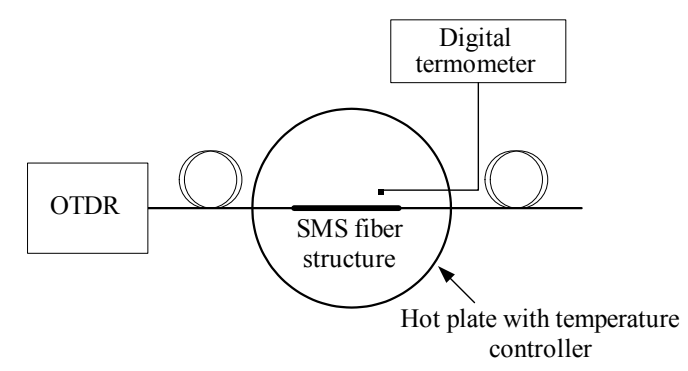

(b)

Fig. 1 Experimental setup diagram: (a) an SMS fiber structure and (b) a schematic setup for measuring the temperature variation in the SMS fiber structure utilizing the OTDR.

\section{Results and discussion}

A typical response of the OTDR measurement from an OTDR Traceview software for the MMF length of $50 \mathrm{~mm}$ is shown in Figs.2(a) and 2(b), for the temperature measurement of $40{ }^{\circ} \mathrm{C}$ and $200{ }^{\circ} \mathrm{C}$, respectively. The OTDR measures the events and 
their locations along the fiber optics network. The abscissa and the ordinate of the graph as in Fig. 2 represent the location (in meter) and the return loss (in $\mathrm{dB}$ ), respectively.

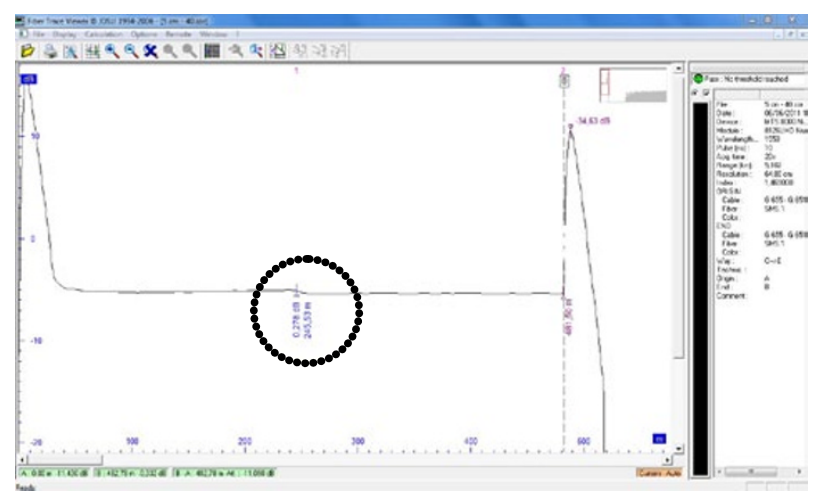

(a)

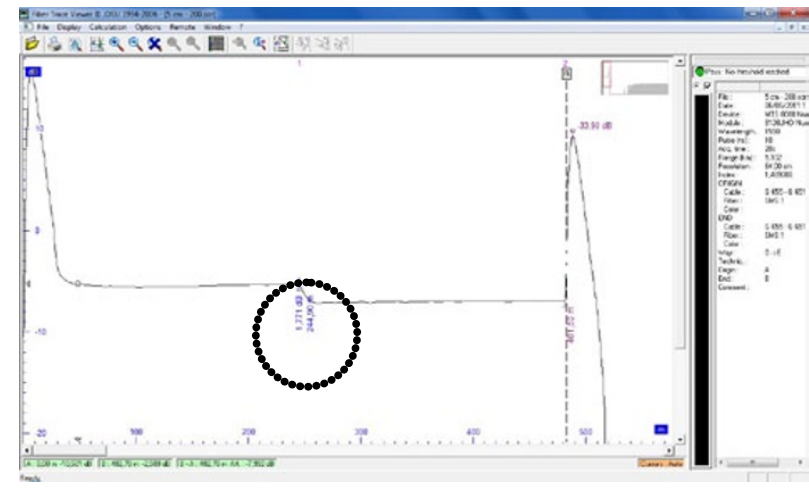

(b)

Fig. 2 A typical response of the OTDR measurement, the presence of the SMS fiber structure and its temperature variation produce the non-reflected event (dashed-circled), at the temperatures of (a) $40{ }^{\circ} \mathrm{C}$ and (b) $200{ }^{\circ} \mathrm{C}$.

There are three events in the optic fiber, from the left to the right as in Figs. 2(a) or 2(b), namely: (1) the reflective event of the fiber connector to the OTDR, (2) the non-reflective event of the SMS fiber structure (dashed-circled), and (3) the reflective event of the fiber end. The presence of the SMS fiber structure along with the temperature variation in the SMS fiber structure causes the non-reflective event. The temperatures of $40{ }^{\circ} \mathrm{C}$ and $200{ }^{\circ} \mathrm{C}$ induce the return loss relative of $0.278 \mathrm{~dB}$ and $1.771 \mathrm{~dB}$, respectively.

Figure 3 shows the return loss relative due to the temperature variation from $40{ }^{\circ} \mathrm{C}$ to $200{ }^{\circ} \mathrm{C}$ with an increment of $5{ }^{\circ} \mathrm{C}$ for the SMS fiber structure with the MMF length of $50 \mathrm{~mm}, 60 \mathrm{~mm}, 70 \mathrm{~mm}$ and $80 \mathrm{~mm}$. One can see the return loss relative strongly depends on the MMF length of the SMS fiber structure. It is also shown that the SMS fiber structure with the chosen MMF length can be utilized as the temperature sensor with different characteristics.

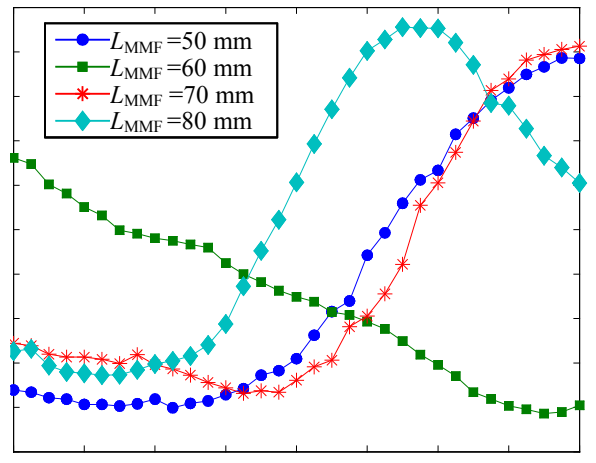

Fig. 3 Return loss relative due to the temperature variation for several MMF lengths of the SMS fiber structure.

The characteristics of each sensor are shown in Table 1. The sensor with the MMF length of $60 \mathrm{~mm}$ had the largest measurement span of $155^{\circ} \mathrm{C}$ with the measurement range of $40{ }^{\circ} \mathrm{C}-195{ }^{\circ} \mathrm{C}$ and a good linearity of $R^{2}=0.992$. However, the MMF length of $80 \mathrm{~mm}$ had the largest sensitivity of $0.0196 \mathrm{~dB} /{ }^{\circ} \mathrm{C}$; assuming the OTDR can detect the minimum value of $0.001 \mathrm{~dB}$, therefore, the measurement resolution of $0.05{ }^{\circ} \mathrm{C}$ can be achieved. Thus, for the temperature sensor purpose, the length of the MMF needs to be chosen carefully with respect to its characteristic performance.

Table 1 Characteristic of the SMS fiber structure temperature sensor.

\begin{tabular}{c|c|c|c|c}
\hline \multirow{2}{*}{ Characteristic } & \multicolumn{4}{|c}{$L_{\mathrm{MMF}}(\mathrm{mm})$} \\
\cline { 2 - 5 } & 50 & 60 & 70 & 80 \\
\hline Range $\left({ }^{\circ} \mathrm{C}\right)$ & $85-195$ & $40-195$ & $115-200$ & $70-150$ \\
\hline Span $\left({ }^{\circ} \mathrm{C}\right)$ & 110 & 155 & 85 & 80 \\
\hline$R^{2}$ & 0.965 & 0.992 & 0.971 & 0.954 \\
\hline Sensitivity $\left(\mathrm{dB} /{ }^{\circ} \mathrm{C}\right)$ & 0.0143 & 0.0085 & 0.0032 & 0.0196 \\
\hline Resolution $\left({ }^{\circ} \mathrm{C}\right)$ & 0.07 & 0.12 & 0.32 & 0.05 \\
\hline
\end{tabular}

The advantage of using the OTDR is to detect some events simultaneously, and it hence can detect 
some sensors. Two SMS fiber structure sensors were developed with the same $L_{\mathrm{MMF}}$ of about $60 \mathrm{~mm}$, and the temperature measurement was carried out.

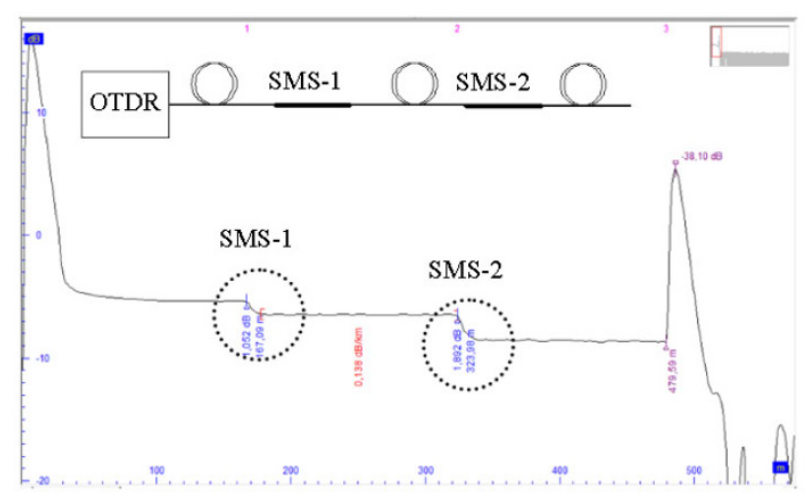

Fig. 4 OTDR response for measurement of two events of SMS-1 and SMS-2 (inset figure: schematic of the setup of the OTDR measurement with two sensors).

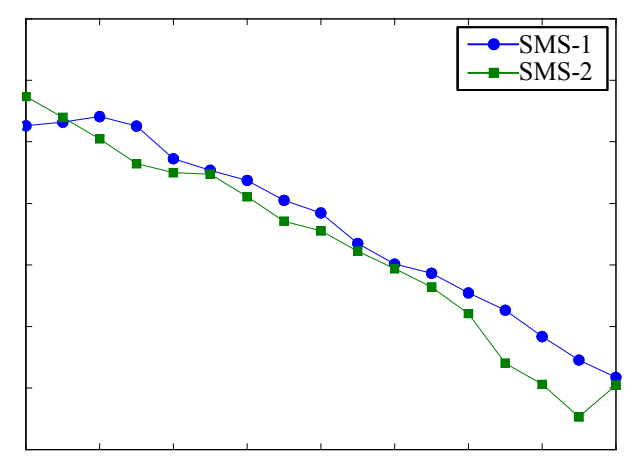

Fig. 5 Return loss relatives of the SMS-1 and SMS-2 due to the temperature variation.

The inset figure in Fig. 4 shows the setup of the OTDR with two SMS fiber structures of SMS-1 and SMS-2. In Fig. 4, it is shown two non-reflected events occur, due to the presence of two SMS fiber structures of SMS-1 and SMS-2. Figure 5 shows the return loss relative due to the temperature variation for the two SMS fiber structure sensors of SMS-1 and SMS-2. Discrepancy between the return loss relative responses of the SMS- 1 and SMS- 2 can be attributed to a residual MMF length error. It can be seen that the OTDR with two temperature sensors of SMS-1 and SMS-2 can perform two-point measurement. Therefore, the OTDR can be utilized to measure the temperature for multi-point.
Assuming each SMS sensor has a span of the return loss relative of $1 \mathrm{~dB}$ and the OTDR has a dynamic range measurement of about $30 \mathrm{~dB}$, the proposed measurement system can be used to measure the temperature for about 30 points.

\section{Conclusions}

The SMS fiber structure sensor and the OTDR interrogator for the temperature measurement were investigated and proposed. Depending on the MMF length of the SMS fiber structure, the temperature sensor characteristic can be varied. It was found that for the MMF length of $60 \mathrm{~mm}$, the measurement temperature range of $40{ }^{\circ} \mathrm{C}-195{ }^{\circ} \mathrm{C}$ could be achieved with a good linearity and the resolution of $0.12{ }^{\circ} \mathrm{C}$. It was also demonstrated the two-point temperature measurement utilizing two SMS fiber structure sensors was made. The proposed temperature measurement system can provide about 30-point temperature measurement using a commercial OTDR for a range of temperature sensor applications.

\section{Acknowledgment}

This work was supported by Science and Technology Research Grant - Indonesia Toray Science Foundation.

Open Access This article is distributed under the terms of the Creative Commons Attribution License which permits any use, distribution, and reproduction in any medium, provided the original author(s) and source are credited.

\section{References}

[1] D. Donlagic and M. Zavrsnik, "Fiber-optic microbend sensor structure," Optics Letters, vol. 22, no. 11, pp. 837-839, 1997.

[2] A. Kumar and R. K. Varshney, "Transmission characteristics of SMS fiber optic sensor structure," Optics Communications, vol. 219, no. 1-6, pp. 215-219, 2003. 
[3] W. S. Mohammed, P. W. E. Smith, and X. Gu, "All-fiber multimode interference bandpass filter," Optics Letters, vol. 31, no. 17, pp. 2547-2549, 2006.

[4] A. M. Hatta, Y. Semenova, Q. Wu, and G. Farrell, "Strain sensor based on a pair of single-mode-multimode-single-mode fiber structures in a ratiometric power measurement scheme," Applied Optics, vol. 49, no. 3, pp. 536-541, 2010.

[5] A. M. Hatta, Y. Semenova, G. Rajan, and G. Farrell, "A voltage sensor based on a singlemode-multimodesinglemode fiber structure," Microwave and Optical Technology Letters, vol. 52, no. 8, pp. 1887-1890, 2010.

[6] Y. Gong, T. Zhao, Y. J. Rao, and Y. Wu, "All-fiber curvature sensor based on multimode interference," Photonics Technology Letters, vol. 23, no. 11, pp. 679-681, 2011.

[7] Q. Wu, Y. Semenova, P. Wang, and G. Farrell, "High sensitivity SMS fiber structure based refractometeranalysis and experiment," Optics Express, vol. 19, no. 9, pp. 7937-7944, 2011.

[8] T. Walbaum and C. Fallnich, "Wavelength tuning of multimode interference bandpass filters by mechanical bending: experiment and theory in comparison," Applied Physics B, vol. 108, no. 1, pp. 117-124, 2012.

[9] S. M. Tripathi, A. Kumar, R. K. Varshney, Y. B. P. Kumar, E. Marin, and J. P. Meunier, "Strain and temperature sensing characteristics of single-modemultimode-single-mode structures," Journal of Lightwave Technology, vol. 27, no. 13, pp. 2348-2356, 2009.
[10] E. Li, X. Wang, and C. Zhang, "Fiber-optic temperature sensor based on interference of selective higher-order modes," Applied Physics Letters, vol. 89, no. 9, pp. 091119-1-091119-3, 2006.

[11] E. Li, "Temperature compensation of multimode interference-based fiber devices," Optics Letters, vol. 32, no. 14, pp. 2064-2066, 2007.

[12] S. Silva, E. G. P. Pachon, M. A. R. Franco, J. G. Hayashi, F. X. Malcata, O. Frazão, et al., "Ultrahigh-sensitivity temperature fiber sensor based on multimode interference," Applied Optics, vol. 51, no. 16, pp. 3236-3242, 2012.

[13] A. M. Hatta, G. Rajan, Y. Semenova, and G. Farrell, "SMS fibre structure for temperature measurement using a simple intensity-based interrogation system," Electronics Letters, vol. 45, no. 21, pp. 1069-1071, 2009.

[14] Q. Wu, Y. Semenova, A. M. Hatta, P. Wang, and G. Farrell, "Bent SMS fibre structure for temperature measurement," Electronics Letters, vol. 46, no. 16, pp. 1129-1130, 2010.

[15] P. S. Reddy, R. S. Prasad, D. S. Gupta, M. S. Shankar, K. Srimannarayana, and P. R. Reddy, "Quasi-distributed fiber Bragg grating array sensor for furnace applications," Photonic Sensors, vol. 2, no. 3, pp. 203-214, 2012.

[16] G. Nosenzo, B. E. Whelan, M. Brunton, D. Kay, and H. Buys, "Continuous monitoring of mining induced strain in a road pavement using fiber Bragg grating sensors," Photonic Sensors, vol. 3, no. 2, pp. 144-158, 2013. 